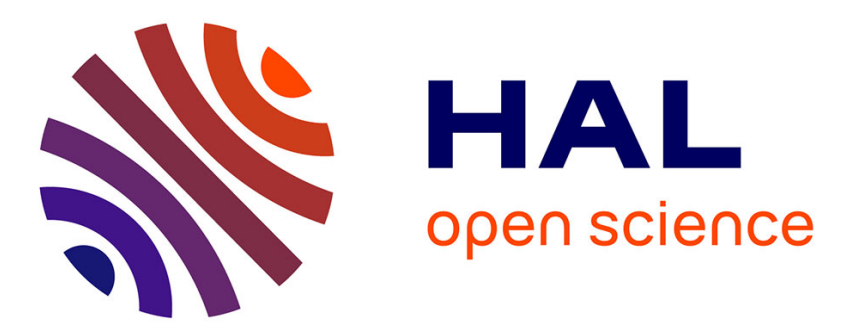

\title{
A spherical cap model of the geomagnetic field over southeast Asia from CHAMP and Swarm satellite observations
}

Le Truong Thanh, Le Huy Minh, Vafi Doumbia, Christine Amory-Mazaudier, Nguyen Thanh Dung, Ha Duyen Chau

\section{To cite this version:}

Le Truong Thanh, Le Huy Minh, Vafi Doumbia, Christine Amory-Mazaudier, Nguyen Thanh Dung, et al.. A spherical cap model of the geomagnetic field over southeast Asia from CHAMP and Swarm satellite observations. Journal of Earth System Science, 2021, 130 (1), pp.13. 10.1007/s12040-02001507-9 . hal-03328750

\section{HAL Id: hal-03328750 \\ https://hal.science/hal-03328750}

Submitted on 30 Aug 2021

HAL is a multi-disciplinary open access archive for the deposit and dissemination of scientific research documents, whether they are published or not. The documents may come from teaching and research institutions in France or abroad, or from public or private research centers.
L'archive ouverte pluridisciplinaire HAL, est destinée au dépôt et à la diffusion de documents scientifiques de niveau recherche, publiés ou non, émanant des établissements d'enseignement et de recherche français ou étrangers, des laboratoires publics ou privés. 


\title{
A spherical cap model of the geomagnetic field over southeast Asia from CHAMP and Swarm satellite observations
}

\author{
Le Truong Thanh ${ }^{1, *}$, Le Huy Minh ${ }^{1}$, Vafi Doumbia ${ }^{2}$, Christine Amory-Mazaudier ${ }^{3,4}$, \\ Nguyen Thanh Dung ${ }^{1}$ and Ha Duyen Chau ${ }^{5}$ \\ ${ }^{1}$ Institute of Geophysics, Vietnam Academy of Science and Technology, Ha Noi, Vietnam. \\ ${ }^{2}$ Laboratoire de Physique de l'Atmosphère et de Mécanique des Fluides, Universite Felix Houphouet Boigny, \\ UFR-SSMT, Abidjan, Côte d'Ivoire. \\ ${ }^{3}$ Laboratoire de Physique des Plasmas, Sorbonne Universités, UPMC Univ. Paris 06, UMR 7648,75005 Paris, \\ France. \\ ${ }^{4}$ T/ICT4D, ICTP, International Centre for Theoretical Physics, Strada Costiera, 11, 34151 Trieste, Italy. \\ ${ }^{5}$ Graduate University of Science and Technology (GUST), 18 Hoang Quoc Viet, Cau Giay, Ha Noi, Vietnam. \\ *Corresponding author. e-mail: igpthanh@gmail.com
}

MS received 4 May 2020; revised 1 September 2020; accepted 19 September 2020

In this paper, Spherical Cap Harmonic Analysis (SCHA) method was applied to model the geomagnetic field over Vietnam and adjacent area between $15^{\circ} \mathrm{S}$ and $25^{\circ} \mathrm{N}$ latitude and $90^{\circ} \mathrm{E}$ and $130^{\circ} \mathrm{E}$ in longitude by using magnetic data recorded on CHAMP and Swarm satellites. The characteristic parameters of the method were set at the maximum index $K_{\text {int }}=8$ for internal fields, the spherical cap half-angle $\theta_{0}=20^{\circ}$. The regional geomagnetic field over Vietnam and adjacent areas are modelled for the two epochs (2007.0 and 2015.0). Comparison between the SCHA regional geomagnetic field intensity and its time variation with those from IGRF was carried out. The geomagnetic field intensity $\left(E_{F}^{S C H A}\right)$ from SCHA model varies between -90 and $98 \mathrm{nT}$ for epoch 2007.0 and between -139 and $143 \mathrm{nT}$ for epoch 2015.0; however, the trends of their time variations are the same over Vietnam. The RMS between the magnetic components from SCHA model and ground observations are in the same order. The amplitude of time variation of total field intensity from SCHA model is about tens nT greater than from IGRF over Vietnam.

Keywords. Spherical cap harmonic analysis; CHAMP and Swarm satellites; regional geomagnetic field; Vietnam and adjacent area.

\section{Introduction}

In Vietnam, from 2000 up to now, many geomagnetic measurements at magnetic observatories, on the sea or in the air have been carried out with the main purpose to study geological structure and mineral exploration. Therefore, it is necessary to have geomagnetic field models specific to this area Published online: 04 February 2021 at these epochs, for obtaining more accurate map of the geomagnetic anomaly fields. Previously, global models such as IGRF are often used. These models represent only the core magnetic field with wavelengths greater than $3000 \mathrm{~km}$, meanwhile modelling a regional magnetic field requires a model that describes both the field from the core and that from a part of the crust. Using the data in 
a small area cannot result in such a model because the orthogonality of the spherical harmonic functions is not satisfied.

Haines (1985a) proposed the spherical cap harmonic analysis (SCHA), which is used widely for modelling the regional magnetic field. In this paper, we use the SCHA method for quiet time geomagnetic data received on CHAMP and Swarm satellites to define the regional geomagnetic model and its time variation over Vietnam and adjacent area. The obtained results will be compared with IGRF-12 model and with data from two magnetic observatories in Vietnam.

\section{Spherical cap harmonic analysis method}

Up to now, many researches using SCHA method, with geomagnetic field data obtained on board satellites or at the earth surface, for modelling the geomagnetic field and its secular variation over different regions, have been carried out for America (e.g., Haines 1985b; Newitt and Haines 1989; Haines and Newitt 1997); for Europe (e.g., Duka 1998; Rotanova and Odintsov 1999; Korte and Haak 2000; Korte and Holme 2003; Verbanac 2007, 2009); for Antarctica (e.g., Torta et al. 2002; Tozzi et al. 2013); for Africa (e.g., Kotzé and Barraclough 1997; Kotzé 2001); and in Asia (e.g., An 2003; Gu et al. 2006; Di et al. 2011; Feng et al. 2016). Recently, Thébault et al. (2004) introduced the revised spherical cap harmonic analysis (RSCHA) modelling by solving the continuation problem with little approximation. The SCHA is a particular case of the R-SCHA method. The representation of the geomagnetic potential in the R-SCHA is similar to the one of the SCHA method, but adds a series of basic functions known as the Mehler functions, but used only one set of Legendre basic functions with the ordering integer index, multiplied by the radial function representing the radial variation of the magnetic field inside the conical region under consideration and the trigonometric sine, cosine functions representing the change in longitude. So R-SCHA method is more suitable for inverse problems involving multilevel data sets which consists of the ground and satellite data (Thébault and Gaya-Piqué 2008). In this paper, we use only the satellite data in the same altitude range and the cap of $20^{\circ}$ half-angle, which is larger than that in Thébault et al. (2004). The modelling of magnetic fields for an area using the SCHA or R-SCHA method using the magnetic field data obtained on satellites has also been of interest to many scientists, e.g., De Santis et al. (1990) and Qamili et al. (2010). Recently, models of lithospheric magnetic field have been established using a combination of magnetic data obtained on some satellites (Swarm, CHAMP...) by Thébault et al. (2013), Qiu et al. (2017), Vervelidou et al. (2018).

According to Haines (1985a), the solution of Laplace's equation in spherical coordinates $(r, \theta$, $\phi)$ for the magnetic potential for both internal (sub-index 'int' in $K$ ) as well as external sources (sub-index 'ext' in $K$ ) over a spherical cap can be written as an expansion:

$$
\begin{aligned}
V(r, \theta, \phi)= & R_{E} \sum_{k=0}^{K_{\text {int }}} \sum_{m=0}^{k}\left(\frac{R_{E}}{r}\right)^{n_{k}(m)+1} P_{n_{k}(m)}^{m}(\cos \theta) \\
& \times\left(g_{k}^{m, i} \cos (m \phi)+h_{k}^{m, i} \sin (m \phi)\right) \\
& +R_{E} \sum_{k=1}^{K_{\text {ext }}} \sum_{m=0}^{k}\left(\frac{r}{R_{E}}\right)^{n_{k}(m)} P_{n_{k}(m)}^{m}(\cos \theta) \\
& \times\left(g_{k}^{m, e} \cos (m \phi)+h_{k}^{m, e} \sin (m \phi)\right),
\end{aligned}
$$

$R_{E}$ is the mean radius of the Earth (in $\mathrm{km}$ ); $P_{n_{k}(m)}^{m}(\cos \theta)$ are the associated Legendre functions that satisfy appropriate boundary conditions (null potential or co-latitudinal derivative at the border of the cap) and have integer order $m$ and generally non-integer degree $n_{k}(m)$.

Coefficients $g_{k}^{m i}, h_{k}^{m i}, g_{k}^{m e}, h_{k}^{m e}$ are the spherical cap harmonic coefficients that determine the model are estimated by the least square inversion based on the observational values of geomagnetic field. When knowing geomagnetic field components (X, $\mathrm{Y}, \mathrm{Z}$ ) and total field (F) at observation point leads to resolve a following linear equation:

$$
\vec{y}=A \vec{m}+\vec{e}
$$

with $\vec{y}$ is the data vector; $\vec{e}$ is error vector; $\vec{m}$ is vector of coefficients $g_{k}^{m i}, h_{k}^{m i}, g_{k}^{m e}, h_{k}^{m e} ; A$ is the operator relating the data vector to the model.

Moreover, recalling that $\vec{B}=-\vec{\nabla} V$, it is possible to provide an analytical expression for the magnetic field $\vec{B}=\vec{B}(r, \theta, \phi, t)$ as well as for the Cartesian components $\mathrm{X}, \mathrm{Y}$ and $\mathrm{Z}$ that can be deduced by proper functions of the derivative of the magnetic potential $V$. These analytical expressions allow the estimation of the values of $X$, $\mathrm{Y}, \mathrm{Z}$ and $\mathrm{F}$ for any value of time $t$ at any given point with coordinates $r, \theta$ and $\phi$ at the Earth's surface and above. 
The number of coefficients depends on the maximum spatial and temporal indices of the expansion, according to equation (1), when $k=$ $K_{\text {int,ext }}^{\max }$ the $n$ number of model coefficients is $\left(K_{\text {int.ext }}^{\max }+1\right)^{2}$.

The root mean square (RMS) between element $E_{j}$ of geomagnetic field calculated from SCHA $\left(E_{j}^{S C H A}\right)$ and from satellite $\left(E_{j}^{O B S}\right)$ is expressed as following:

$$
R M S_{j}=\sqrt{\frac{1}{n} \sum_{i=1}^{n}\left(E_{j, i}^{S C H A}-E_{j, i}^{O B S}\right)^{2}},
$$

with $n$, the number of observation data.

When applying spherical cap harmonic analysis, it is recommended to remove a global spherical harmonic potential from the total potential in order to improve convergence as well as extrapolation beyond the spherical cap boundary (e.g., Haines 1985a). In this study, the IGRF-12 model by Thébault et al. (2015) in corresponding epoch was subtracted from the CHAMP and Swarm observed magnetic data. The full regional model then consists of the IGRF-12 model and SCHA model that describes the part of the field, which is not represented by the IGRF-12 model:

$$
\Delta E_{j}=E_{j}^{O B S}-E_{j}^{I G R F},
$$

where $E_{j}^{I G R F}$ is the corresponding element of the magnetic field from the IGRF-12 model, $\Delta E_{j}$ is geomagnetic data using for calculation of the coefficients of SCHA model.

\section{Selection of satellites data and processing}

The SCHA method is applied for modelling the geomagnetic field for Vietnam and adjacent area between $15^{\circ} \mathrm{S}-25^{\circ} \mathrm{N}$ in latitude and $90^{\circ}-130^{\circ} \mathrm{E}$ in longitude (figure 1) at two epochs 2007.0 and 2015.0. The X, Y, Z components and F recorded on CHAMP satellite from Jan 1, 2006 to Dec 31, 2007, and the magnetic field measurements by the lowest pair of the Swarm satellites (A and C) from Jan 1, 2014 to Dec 31, 2015, are used. The area covered for this study extends between $90^{\circ}-130^{\circ} \mathrm{E}$ in longitude and $15^{\circ} \mathrm{S}-25^{\circ} \mathrm{N}$ in latitude (figure 1).

As in Torta et al. (1993), Kotzé (2001) and Qamili et al. (2010), the satellite data in magnetic quiet periods corresponding to the magnetic indices $K_{p} \leq 3$ and $\left|D_{s t}\right| \leq 20 \mathrm{nT}$ have been selected. Data belonging to the midnight local times (LT) between 20:00 and 05:00 were selected in order to minimize the influence of the diurnal solar quiet variation $(\mathrm{Sq})$. The data with such selections reduce mainly the effects of the external magnetic field and the magnetic disturbances.

As results, we obtained a total of 51,202 data points of three components and scalar with an altitude of about $330 \sim 360 \mathrm{~km}$ on CHAMP satellite, and 61,312 data points with an altitude of about $440 \sim 510 \mathrm{~km}$ on Swarm satellites. Figure 1 shows the CHAMP satellite passes over Vietnam and adjacent region for the first 2 months of 2007 .

Since the data were continuously measured during long time period, the effect of the secular variation was removed. Using the secular variation model of IGRF-12 with coefficients $n d o t=1-8$, all the selected data have been adjusted to epoch 2007.0 (00:00 January 1st, 2007) for CHAMP satellite data and to epoch 2015.0 for Swarm satellites data. According to Haines (1985a), the global magnetic field must be removed from data by using IGRF-12 with coefficients of degrees $n=1-13$ before the inversion.

The density of satellite data coverage is so high that, different values of the magnetic field may be observed at different altitudes above the same location. As a consequence, the data distribution may not be uniform over the region. In addition, the total input data for inversion can be very large. As in Rotanova and Odintsov (1999) and Duka (1998), the data are gridded before the computation in this paper. The grid of $0.2^{\circ} \times 0.2^{\circ}$ was used. The values of the geomagnetic field components and of observation altitudes in each cell, are chosen as the mean values that were observed at all points in the cell of concern. These value areas signed to the center of the cell at the corresponding mean altitude. In addition, the values with large errors in the cell, which are deviated by $\pm 2.51 \mathrm{nT}$ (and $\pm 5 \mathrm{~km}$ for altitude) from the mean were removed. The number of data used for gridding is 46,375 data points and 52,973 ones for CHAMP and Swarm, respectively. In this paper using the gridding data and nongridding data for inversion, we found that the RMS between SCHA model and input with gridding data is of $2.25 \mathrm{nT}$, less than with the one of non-gridding data for CHAMP data and $1.63 \mathrm{nT}$ for Swarm (for F), correspondingly. Such outlier removing and data gridding allow to obtain better SCHA model.

The area of this study is as wide as $40^{\circ} \times 40^{\circ}$ in latitude and longitude. Therefore, the spherical cap half angle of $20^{\circ}$ is selected, the cap center is 


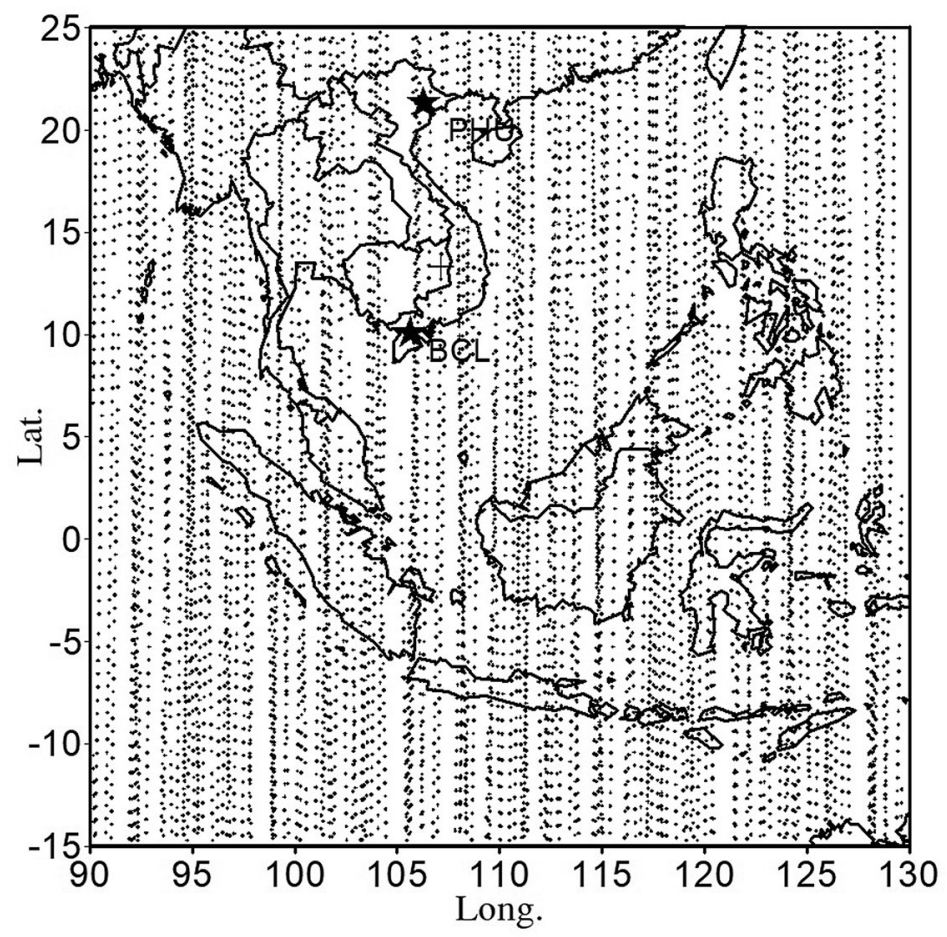

Figure 1. Data distribution over Vietnam and adjacent region: CHAMP satellite data from Jan 1 to Feb 28,2007 (triangular) and location of the PHU and BCL magnetic observatories in Vietnam (star).

located at location $5^{\circ} \mathrm{N}$ latitude and $110^{\circ} \mathrm{E}$ longitude.

\section{Results and discussions}

\subsection{Model of regional magnetic field for Vietnam and adjacent area}

In order to take into account, the external field sources as Kotzé (2001), the value of $K_{\text {ext }}=2$ is used. Table 1 shows the model coefficients for external potential calculated respectively from CHAMP and Swarm satellites. These tables also show the non-integral degrees of $n_{k}(m)$ for the spherical cap. The first coefficient $g_{1}^{0, e}=14.03 \mathrm{nT}$ calculated from CHAMP data is slightly smaller than $g_{1}^{0, e}=15.49 \mathrm{nT}$ obtained from Swarm data. These two values of $g_{1}^{0, e}$ are considered as close to $g_{1}^{0, e}=16.91 \mathrm{nT}$, which was obtained by Kotzé (2001) using Orsted satellite data, however, they are smaller than the $g_{1}^{0, e}=20.4 \mathrm{nT}$ obtained by Langel and Estes (1985) using satellite MAGSAT data. Except $g_{1}^{0, e}$ the coefficients for 2007 and 2015 epochs are almost identical, this means that the
Table 1. The coefficients $g_{k}^{m, e}, h_{k}^{m, e}$ for external field from CHAMP and Swarm data.

\begin{tabular}{|c|c|c|c|c|}
\hline$k$ & $m$ & $n_{k}(m)$ & $g_{k}^{m, e}$ & $h_{k}^{m, e}$ \\
\hline \multicolumn{5}{|c|}{ CHAMP data } \\
\hline 1 & 0 & 6.3832 & 14.03 & \\
\hline 1 & 1 & 4.8432 & -4.49 & -3.72 \\
\hline 2 & 0 & 10.4885 & -5.65 & \\
\hline 2 & 1 & 10.0815 & 0.93 & 1.11 \\
\hline 2 & 2 & 8.3553 & -0.08 & -0.18 \\
\hline \multicolumn{5}{|c|}{ Swarm data } \\
\hline 1 & 0 & 6.3832 & 15.49 & \\
\hline 1 & 1 & 4.8432 & -4.21 & -3.98 \\
\hline 2 & 0 & 10.4885 & -5.13 & \\
\hline 2 & 1 & 10.0815 & 0.77 & 1.29 \\
\hline 2 & 2 & 8.3553 & -0.11 & -0.21 \\
\hline
\end{tabular}

contribution of the coefficient $g_{1}^{0, e}$ is the most important in the difference of the external field in the two epochs. The value of $g_{1}^{0, e}$ at 2015 is greater than the one at 2007, this means that the external field at 2015 is greater than the one at 2007 . It can be explained by the fact that the solar activity in 2015 is greater than the one in 2007. After removal of the external field, the data have been used to determine the internal coefficients. 
In order to choose the optimal $K_{\text {int }}$ value, the inversions are carried out with different $K_{\text {int }}$ values from $K_{\text {int }}=1$ to 10 . The RMS deviations between the observation data and modelled $\mathrm{X}, \mathrm{Y}$ and $\mathrm{Z}$ components were calculated. The optimal $K_{\text {int }}$ was selected from the plot representing the RMS deviations against the given orders, $n$ (figure $2 \mathrm{a}$ and $\mathrm{b}$ ). We found that the values of RMS tend to decrease with increasing $K_{\text {int }}$. As the RMS values of the three components of the magnetic field are small and relatively stable when $K_{\text {int }} \geq 8, K_{\text {int }}=8$ is used for the calculations.

Tables 2 and 3 shows the 81 coefficients calculated from CHAMP and Swarm data, respectively. According to De Santis et al. (1999), the value of the coefficient $g_{0}^{0, i}$ depends on mean of the magnetic field and half-angle $\theta_{0}$. For this area, with selected $\theta_{0}=20^{\circ}$ we have $g_{0}^{0, i}=217.03 \mathrm{nT}$ for CHAMP data and $g_{0}^{0, i}=261.18 \mathrm{nT}$ for Swarm data. These values are comparable to $g_{0}^{0, i}=358.5 \mathrm{nT}$ obtained by $\mathrm{Gu}$ et al. (2006) for the Chinese region $\left(\theta_{0}=30^{\circ}\right)$. When

(a)

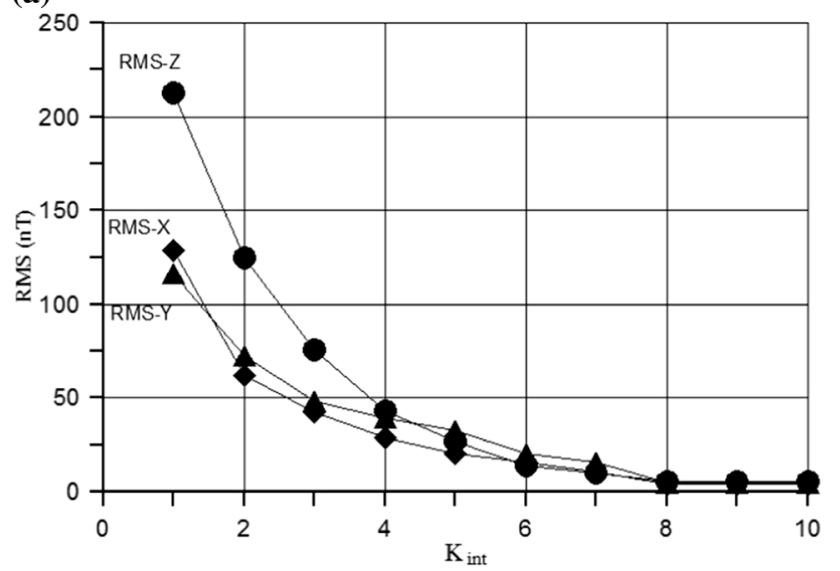

(b)

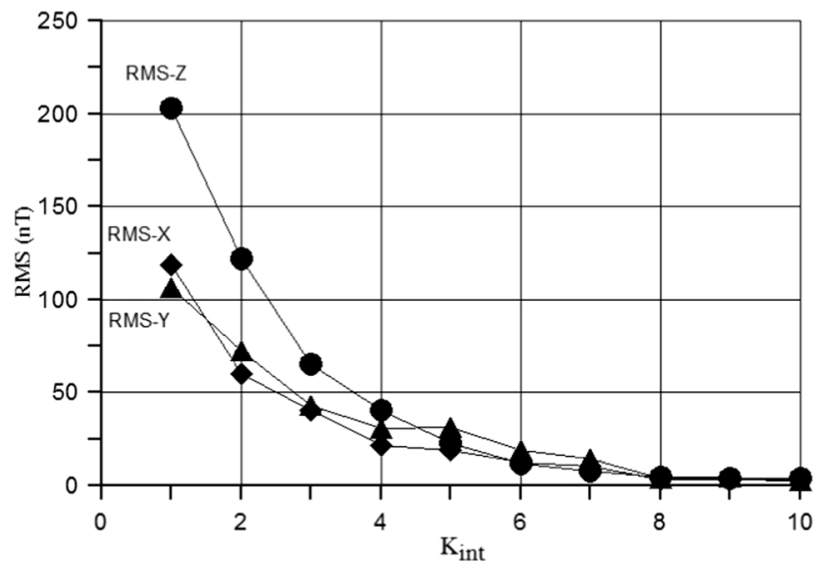

Figure 2. The RMS corresponding to X, Y, Z with $K_{\text {int }}$ from 1 to 10 from (a) CHAMP data and (b) Swarm data. the coefficients of the spherical cap harmonic are determined, the model of the regional geomagnetic field $E_{j}^{R G F}$ is obtained for each epoch by summing the geomagnetic components from SCHA model $E_{j}^{S C H A}$ and IGRF-12 model $E_{j}^{I G R F}$ as:

$$
E_{j}^{R G F}=E_{j}^{S C H A}+E_{j}^{I G R F},
$$

where $E_{j}$ refers to any component of the magnetic field.

For the internal field, the model was restricted to $K_{\text {int }}=8$ and a half-cap angle of $20^{\circ}$, resulting in a minimum wavelength resolution of approximately $1000 \mathrm{~km}$.

As results, figures 3 and 4 show the elements (D, I, X, Y, Z, F) of the regional geomagnetic field model for the epochs 2007.0 and 2015.0 correspondingly. The morphologies of the different elements are similar for the two epochs, but amplitudes are different. Detailed comments on the magnetic components in the research areas are given as follows:

- The spatial distributions of D (figures 3a and 4a) and Y (figures 3d and 4d) are similar in the two epochs, they reached their greatest values in the southeastern corner of the study area and decreased in both latitude and longitude. D varies between $-6.95^{\circ}$ and $3.52^{\circ}$ for epoch 2007.0 and between $-5.41^{\circ}$ and $2.67^{\circ}$ for epoch 2015.0, $\mathrm{Y}$ varies between -3829 and $2132 \mathrm{nT}$ for epoch 2007.0 and between -3354 and $1642 \mathrm{nT}$ for epoch 2015.0.

- The spatial distributions of I (figures $3 \mathrm{~b}$ and $4 \mathrm{~b}$ ) and Z (figures 3e and 4e) are similar for the two epochs. The contours are evenly spaced, along the east-west direction, and slightly inclined with respect to the meridians. I and $\mathrm{Z}$ are the smallest in the south, with increasing values towards the north. I varies between $-49.21^{\circ}$ and $37.23^{\circ}$ for epoch 2007.0 and between $-48.52^{\circ}$ and $38.85^{\circ}$ for epoch 2015.0. Z varies between -36958 and $28400 \mathrm{nT}$ for epoch 2007.0 and between -36344 and $29551 \mathrm{nT}$ for epoch 2015.0. The zero line of both I and Z (magnetic equator) is at about $8^{\circ} \mathrm{N}$.

- The distribution of the X component (figures 3c, $4 \mathrm{c})$ has a maximum located at $\left(9^{\circ} \mathrm{N}, 98^{\circ} \mathrm{E}\right)$ at epoch 2007.0, this large peak moves down southwest a little in epoch 2015.0 at the location $\left(8.5^{\circ} \mathrm{N}, 97.3^{\circ} \mathrm{E}\right) . \mathrm{X}$ is between 31392 and 41458 nT for epoch 2007.0, and between 32005 and $41582 \mathrm{nT}$ for epoch 2015.0. 
Table 2. The coefficients of the 8-order SCHA for epoch 2007.0.

\begin{tabular}{rccccccrrrrr}
\hline$k$ & $m$ & $g_{k}^{m, i}$ & $h_{k}^{m, i}$ & $k$ & $m$ & $g_{k}^{m, i}$ & $h_{k}^{m, i}$ & $k$ & $m$ & $g_{k}^{m, i}$ & $h_{k}^{m, i}$ \\
\hline 0 & 0 & 217.03 & & 5 & 0 & -150.2 & & 7 & 2 & 18.92 & 22.66 \\
1 & 0 & -126.1 & & 5 & 1 & -75.46 & 13.53 & 7 & 3 & -5.13 & -12.99 \\
1 & 1 & -43.31 & 55.48 & 5 & 2 & 84.26 & 9.39 & 7 & 4 & -0.99 & -9.9 \\
2 & 0 & 191.16 & & 5 & 3 & -32.33 & -29.22 & 7 & 5 & 1.01 & 4.49 \\
2 & 1 & 78.38 & -46.21 & 5 & 4 & -19.45 & -14.24 & 7 & 6 & -5.51 & -8.03 \\
2 & 2 & -27.96 & 22.02 & 5 & 5 & -0.01 & 8.54 & 7 & 7 & -2.1 & 4.96 \\
3 & 0 & -208.7 & & 6 & 0 & 84.35 & & 8 & 0 & 5.54 & -0.53 \\
3 & 1 & -112.1 & 47.91 & 6 & 1 & 65.28 & -35.11 & 8 & 1 & 2.38 & -2.95 \\
3 & 2 & 45.33 & -30.81 & 6 & 2 & -54.46 & -27.02 & 8 & 2 & 0.08 \\
3 & 3 & 15.28 & -9.6 & 6 & 3 & 44.94 & 24.60 & 8 & 3 & 2.12 & 2.28 \\
4 & 0 & 201.95 & & 6 & 4 & 31.31 & 15.15 & 8 & 4 & -1.41 & 0.79 \\
4 & 1 & 105.69 & -31.67 & 6 & 5 & -10.64 & -8.43 & 8 & 5 & -0.95 & 0.73 \\
4 & 2 & -83.79 & -6.18 & 6 & 6 & 8.54 & -6.18 & 8 & 6 & 1.7 & -1.04 \\
4 & 3 & 31.57 & 22.01 & 7 & 0 & -28.33 & & 8 & 7 & -0.39 & -0.42 \\
4 & 4 & 20.09 & 7.34 & 7 & 1 & -12.24 & 31.25 & 8 & 8 & 1.39 & -1.32 \\
\hline
\end{tabular}

Table 3. The coefficients of the 8-order SCHA for epoch 2015.0.

\begin{tabular}{rcccccccccrr}
\hline$k$ & $m$ & $g_{k}^{m, i}$ & $h_{k}^{m, i}$ & $k$ & $m$ & $g_{k}^{m, i}$ & $h_{k}^{m, i}$ & $k$ & $m$ & $g_{k}^{m, i}$ & $h_{k}^{m, i}$ \\
\hline 0 & 0 & 261.18 & & 5 & 0 & -200.12 & & 7 & 2 & -2.07 & -31.01 \\
1 & 0 & -152.12 & & 5 & 1 & -315.36 & 51.17 & 7 & 3 & -4.11 & -10.11 \\
1 & 1 & -160.12 & 64.37 & 5 & 2 & 140.11 & -72.1 & 7 & 4 & -9.29 & -11.2 \\
2 & 0 & 205.11 & & 5 & 3 & -81.55 & -87.16 & 7 & 5 & 15.72 & 5.41 \\
2 & 1 & 109.48 & -59.22 & 5 & 4 & 50.67 & -26.51 & 7 & 6 & -9.55 & -5.11 \\
2 & 2 & -55.11 & 15.12 & 5 & 5 & 19.12 & 11.52 & 7 & 7 & -1.13 & 3.51 \\
3 & 0 & -302.12 & & 6 & 0 & 90.13 & & 8 & 0 & 1.02 & 1.16 \\
3 & 1 & -389.29 & 70.25 & 6 & 1 & 162.37 & -39.12 & 8 & 1 & -3.25 \\
3 & 2 & 162.26 & -35.15 & 6 & 2 & -50.60 & 59.17 & 8 & 2 & 3.17 & 1.64 \\
3 & 3 & -15.23 & -44.46 & 6 & 3 & 78.32 & 46.4 & 8 & 3 & 0.11 & -2.42 \\
4 & 0 & 477.65 & & 6 & 4 & -71.96 & 21.42 & 8 & 4 & -1.22 & 3.8 \\
4 & 1 & 211.58 & -60.13 & 6 & 5 & -25.46 & 28.41 & 8 & 5 & -4.6 & 1.11 \\
4 & 2 & -212.1 & 60.75 & 6 & 6 & 20.41 & -8.4 & 8 & 6 & 2.56 & 0.12 \\
4 & 3 & 54.22 & 81.95 & 7 & 0 & -85.1 & & 8 & 7 & -1.06 & -1.02 \\
4 & 4 & -6.27 & 20.14 & 7 & 1 & -59.2 & 14.22 & 8 & 8 & 0.37 & -0.25 \\
\hline
\end{tabular}

- The total field F (figures 3f, 4f) reaches the smallest value at about $7^{\circ} \mathrm{N}$ latitude in one of the two epochs and gradually increases to the north and south of the study area. F is between 38624 and $49517 \mathrm{nT}$ for epoch 2007.0, and between 38692 and $49186 \mathrm{nT}$ for epoch 2015.0.

The RMS of D, I, X, Y, Z, F components of geomagnetic field between SCHA model and satellite data at two epochs 2007.0 and 2015.0 are shown in table 4 . These RMS values from the Swarm data are smaller than that from CHAMP data and they are consistent with the results of the Korzé (2001) as 4.1 arcmin for D, $16.6 \mathrm{nT}$ for F, $22.7 \mathrm{nT}$ for $\mathrm{H}$, and $17.9 \mathrm{nT}$ for $\mathrm{Z}$.

\subsection{Comparison with observatory data}

In this paragraph, the SCHA method described above is evaluated against satellite and groundbased geomagnetic data recorded at two geomagnetic observatories in Vietnam. The model results are compared with the observed elements of the geomagnetic field at $\mathrm{Phu}$ Thuy, $\mathrm{PHU}\left(21.2^{\circ} \mathrm{N}\right.$, $\left.105.57^{\circ} \mathrm{E}\right)$ and Bac Lieu, BCL $\left(9.28^{\circ} \mathrm{N}, 105.73^{\circ} \mathrm{E}\right)$. In selecting satellite data, we used the mean values of magnetic data around the midnight from 20:00 to 05:00 (LT) on quiet days $\left(K_{p} \leq 3\right.$ and $\left|D_{s t}\right| \leq 20$ $\mathrm{nT})$. The RMS of $\mathrm{X}, \mathrm{Y}, \mathrm{Z}$ components between the SCHA modelled data at PHU and BCL at epoch 2007.0 and epoch 2015.0 are shown in table 5. The 
(a)

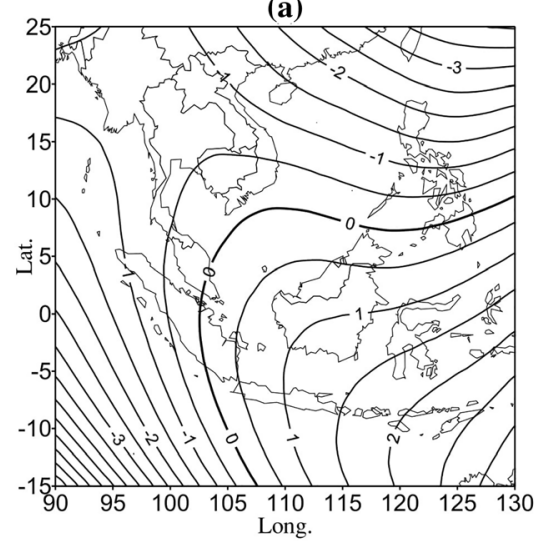

(d)

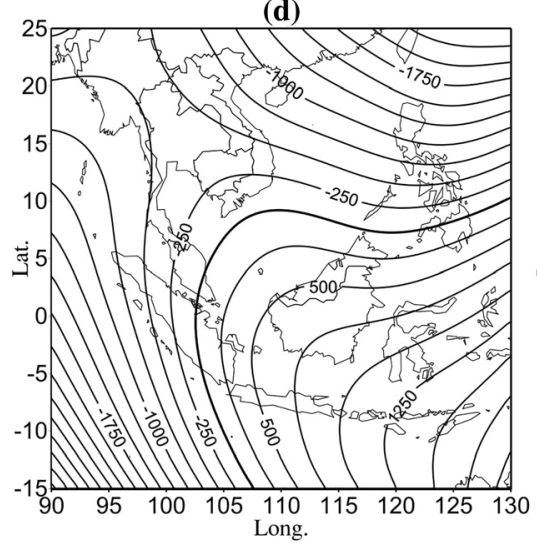

(b)

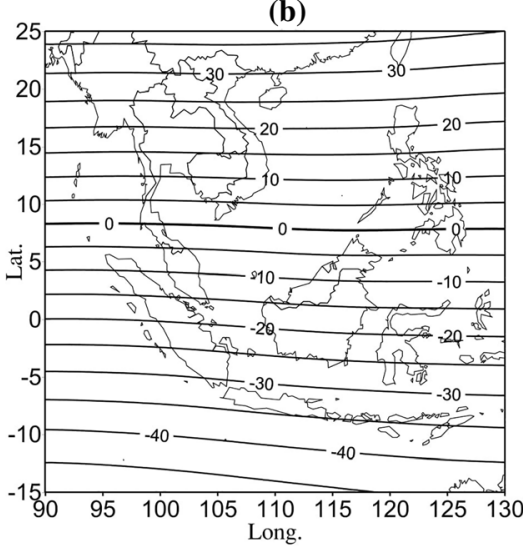

(e)

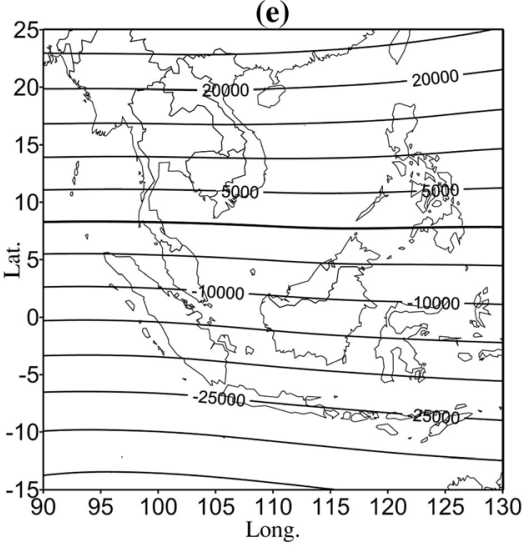

(c)

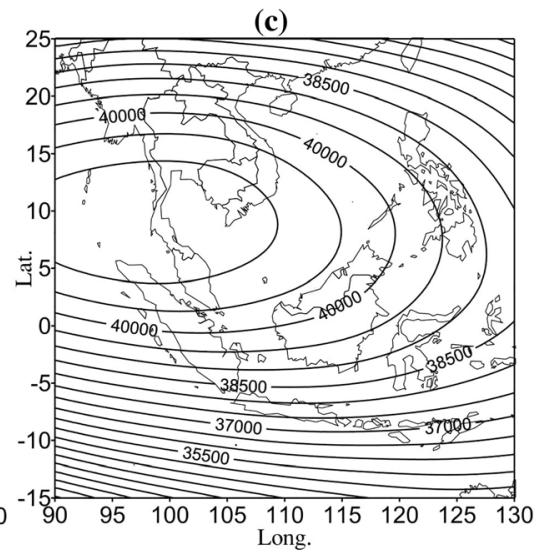

(f)

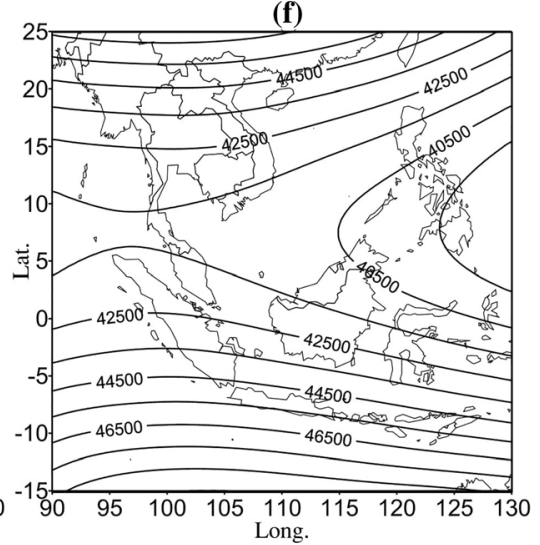

Figure 3. The regional geomagnetic field for the epoch 2007.0; (a) $\mathrm{D}\left({ }^{\circ}\right),(\mathbf{b}) \mathrm{I}\left({ }^{\circ}\right),(\mathbf{c}) \mathrm{X}(\mathrm{nT}),(\mathbf{d}) \mathrm{Y}(\mathrm{nT}),(\mathbf{e}) \mathrm{Z}(\mathrm{nT})$, and $(\mathbf{f}) \mathrm{F}(\mathrm{nT})$.

values of the RMS related to Swarm data (epoch 2015.0) are found to be smaller than that related to CHAMP data (epoch 2007.0). This may be due to the fact that the quality of the data obtained from the Swarm satellites is better than the one from CHAMP satellite.

Table 5 showed that the RMSs between SCHA model and geomagnetic field received on satellite or from ground observations are in the same order of magnitude. Note that, the regional geomagnetic field model was calculated at the height of the satellites or at the Earth's surface when calculating for the data collected from satellite or at geomagnetic stations. This also shows the rationality of using satellite data for modelling the regional geomagnetic field at ground level.

\subsection{The $E_{F}^{S C H A}$ at two epochs}

The geomagnetic field $E_{F}^{S C H A}$ calculated from the SCHA coefficients as described above, represents regional magnetic field of the study area as mentioned above. Thus, figure $5(\mathrm{a}$ and $\mathrm{b})$ shows the SCHA total magnetic field $\left(E_{F}^{S C H A}\right)$ over the south-east Asia, for the epochs 2007.0 and 2015.0, respectively. We notice that the shapes of the two maps are very similar, although the magnitudes are different. The $E_{F}^{S C H A}$ varies between -90 and $98 \mathrm{nT}$ for epoch 2007.0 and between -139 and $143 \mathrm{nT}$ for epoch 2015.0. In figure 5(a), $E_{F}^{S C H A}$ values are mostly negative over the whole research area (dotted line contour), except a few areas where the $E_{F}^{S C H A}$ exhibits positive value, i.e., in the northern Philippines, southern Taiwan and in the southeast of Indonesia or Vietnam, especially in the areas of great magnitude as Myanmar, Philippines, central Vietnam East sea, Indonesia. But in figure 5(b), there is an area of $E_{F}^{S C H A}$ positive values, which decreases towards the regions of negative values such as in Vietnam and in the western margin. Another notice is that over most area in Vietnam, Laos, Campuchia and Thailand territories, the amplitudes of $E_{F}^{S C H A}$ have opposite signs in two epochs. Thus, these results show the stability of the SCHA method over time, but the resulting magnetic field model represents only part of the magnetic field that the IGRF model does not account for. The magnetic field amplitudes are of 

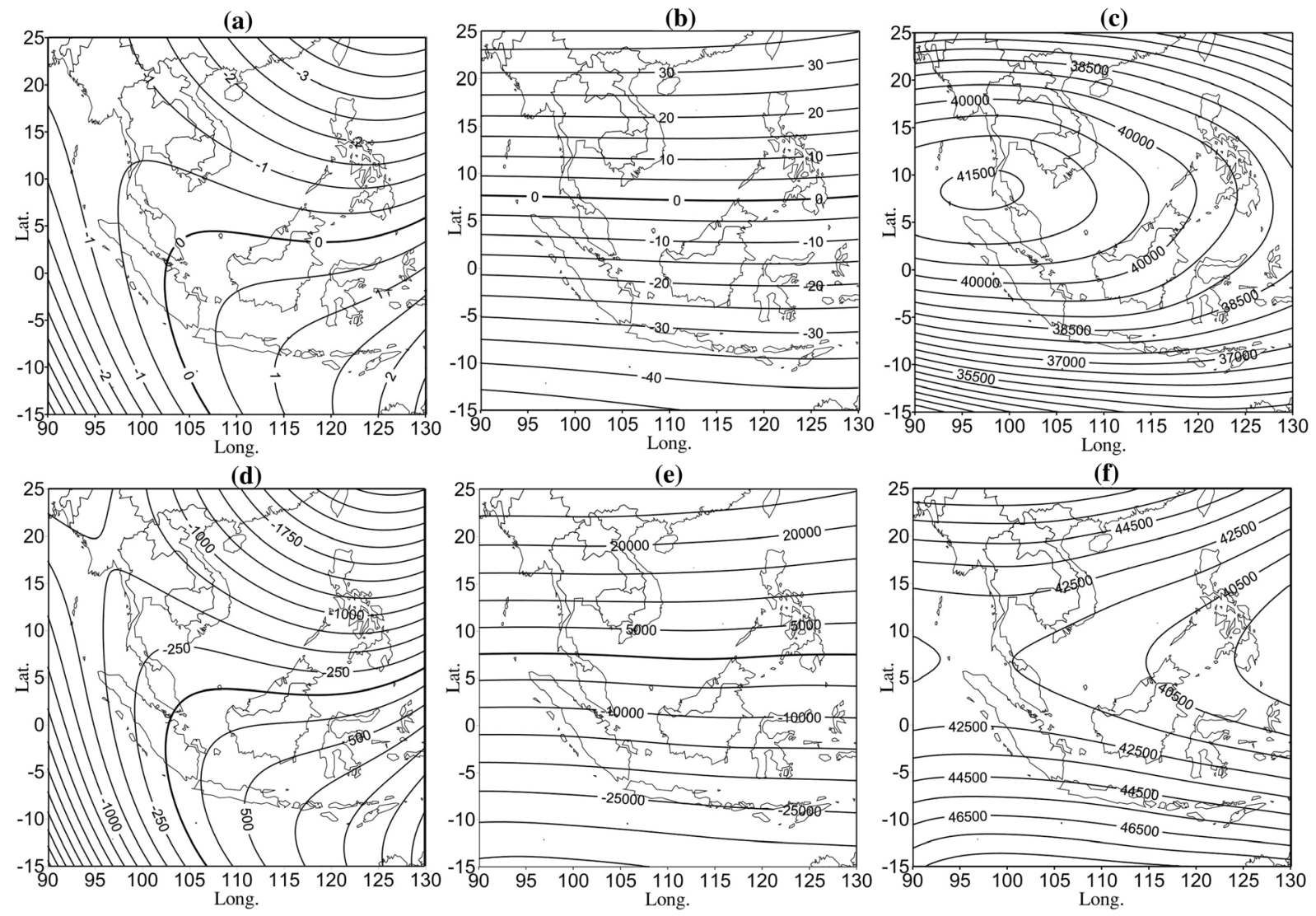

Figure 4. The regional geomagnetic field for the epoch 2015.0; (a) $\mathrm{D}\left({ }^{\circ}\right),(\mathbf{b}) \mathrm{I}\left(^{\circ}\right),(\mathbf{c}) \mathrm{X}(\mathrm{nT}),(\mathbf{d}) \mathrm{Y}(\mathrm{nT}),(\mathbf{e}) \mathrm{Z}(\mathrm{nT})$, and (f) $\mathrm{F}(\mathrm{nT})$.

Table 4. The RMS between satellite data and regional geomagnetic field models for epoch $200 \% .0$ and 2015.0.

\begin{tabular}{lcccccc}
\hline & $\begin{array}{c}\text { RMS-D } \\
(\operatorname{arc} \min )\end{array}$ & $\begin{array}{c}\text { RMS-I } \\
(\operatorname{arc} \min )\end{array}$ & $\begin{array}{c}\text { RMS-X } \\
(\mathrm{nT})\end{array}$ & $\begin{array}{c}\text { RMS-Y } \\
(\mathrm{nT})\end{array}$ & $\begin{array}{c}\text { RMS-Z } \\
(\mathrm{nT})\end{array}$ & $\begin{array}{c}\text { RMS-F } \\
(\mathrm{nT})\end{array}$ \\
\hline Epoch 2007.0 & 3.23 & 2.14 & 4.15 & 4.64 & 5.31 & 12.52 \\
Epoch 2015.0 & 2.95 & 1.83 & 3.22 & 3.83 & 4.41 & 11.54 \\
\hline
\end{tabular}

Table 5. The RMS of X, Y,Z components for epoch 2007.0 and 2015.0 at PHU and BCL observatories.

\begin{tabular}{lccccccc}
\hline & \multicolumn{3}{c}{ Epoch 2007.0 (CHAMP data) } & & \multicolumn{3}{c}{ Epoch 2015.0 (Swarm data) } \\
\cline { 2 - 3 } & $\begin{array}{c}\text { RMS-X } \\
(\mathrm{nT})\end{array}$ & $\begin{array}{c}\text { RMS-Y } \\
(\mathrm{nT})\end{array}$ & $\begin{array}{c}\text { RMS-Z } \\
(\mathrm{nT})\end{array}$ & & $\begin{array}{c}\text { RMS-X } \\
(\mathrm{nT})\end{array}$ & $\begin{array}{c}\text { RMS-Y } \\
(\mathrm{nT})\end{array}$ & $\begin{array}{c}\text { RMS-Z } \\
(\mathrm{nT})\end{array}$ \\
\hline PHU & 3.31 & 3.42 & 3.05 & & 2.25 & 3.14 & 2.51 \\
BCL & 3.73 & 3.13 & 3.22 & & 3.12 & 3.05 & 2.92 \\
\hline
\end{tabular}

about hundreds of nT, which may affect other studies, such as the regional magnetic anomaly maps. The difference of $E_{F}^{S C H A}$ at two epochs represents the fact that it varies over time; the magnetic field calculated by the SCHA method includes the crustal field and some part of the core field, remove the core field from the observation data by the IGRF model $(n=13)$ is incomplete.

\subsection{Time variation of regional geomagnetic field}

Based on the SCHA model calculation of the regional geomagnetic field over Vietnam and 
(a)

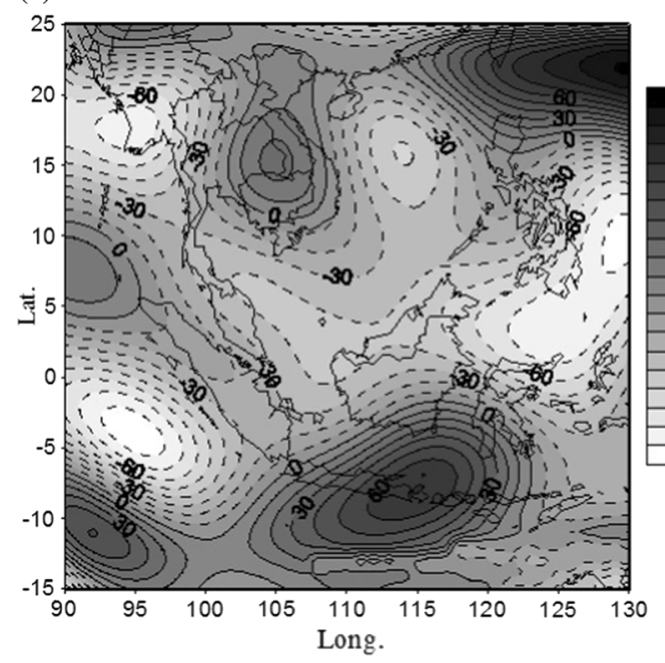

(b)

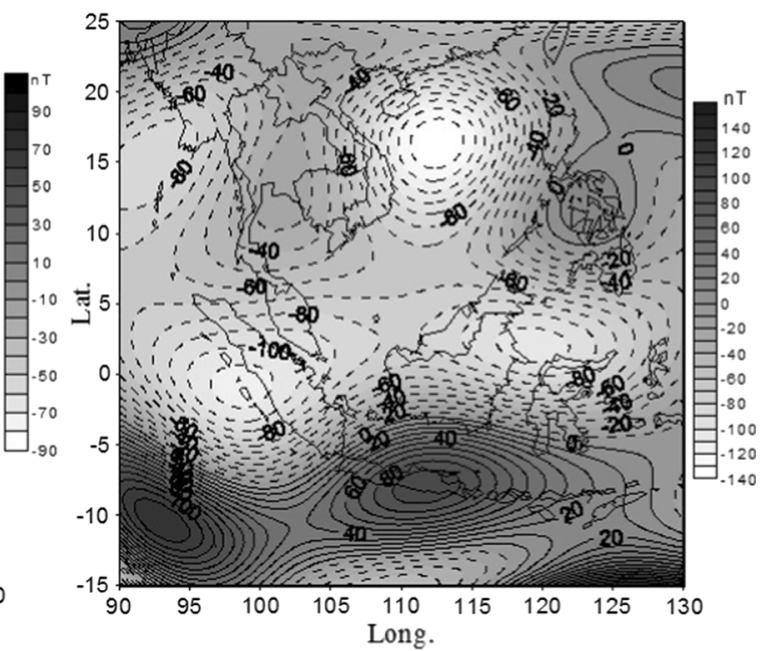

Figure 5. The $E_{F}^{S C H A}(\mathrm{nT})$ at two epochs; (a) epoch 2007.0, (b) epoch 2015.0.

(a)

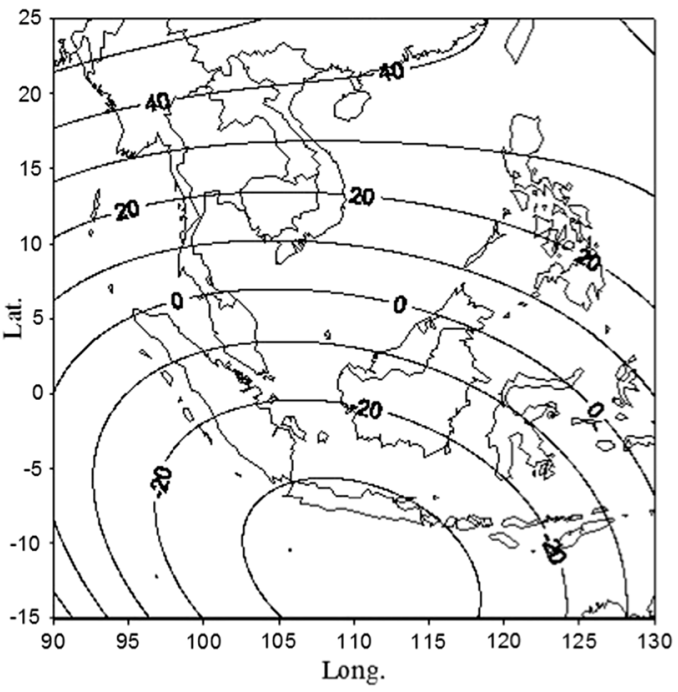

(b)

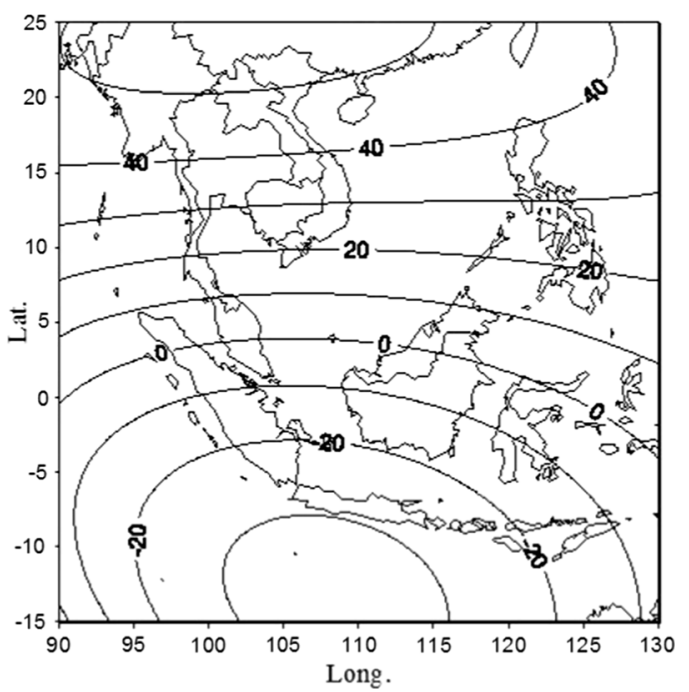

Figure 6. The time variation of total field (F) in period 2007-2015; (a) $S E_{F}^{R G F}$ from SCHA model and (b) $S E_{F}^{I G R F}$ from IGRF-12 model.

adjacent region, for the epochs 2007.0 and 2015.0, the average time variations of the geomagnetic field components can be calculated as follows:

$$
S E_{j}^{R G F}=\left(E_{j}^{R G F-2015}-E_{j}^{R G F-2007}\right) /(2015-2007),
$$

where $E_{j}^{R G F-2007}$ and $E_{j}^{R G F-2015}$ are the components of the regional geomagnetic field during epochs 2007.0 and 2015.0, respectively; $S E_{j}^{R G F}$ is the time variation of the regional geomagnetic field.

Figure 6 compares calculated $S E_{F}^{R G F}$ (figure 6a) with $S E_{F}^{I G R F}$ from IGRF-12 model (figure $6 \mathrm{~b}$ ). In figure 6(a), it can be noticed that $S E_{F}^{R G F}$ varies between -35.1 and $56.4 \mathrm{nT} / \mathrm{yr}$. The strongest negative change is observed in the southern part of the study area. There is a tendency for negative anomalies to occur at the location $12^{\circ} \mathrm{S}, 110.5^{\circ} \mathrm{E}$. In the northern part of study area, the values of $S E_{F}^{R G F}$ gradually increase.

The contour maps shown in figure $6(\mathrm{a}$ and $\mathrm{b})$ are almost similar. The amplitudes of $S E_{F}^{I G R F}$, which varies from -34.4 and $54.3 \mathrm{nT} / \mathrm{yr}$, are in the same range as $S E_{F}^{R G F}$ (-35.1 and $\left.56.5 \mathrm{nT} / \mathrm{yr}\right)$. The negative peak in the $S E_{F}^{I G R F}$ map is located farther south than that of the $S E_{F}^{R G F}$ (on $13.5^{\circ} \mathrm{S}, 108.5^{\circ} \mathrm{E}$ with respect to $\left.12^{\circ} \mathrm{S}, 110.5^{\circ} \mathrm{E}\right)$. In Vietnam 
territory, the difference in amplitude between these two maps is of about tens of nT $\left(S E_{F}^{R G F}\right.$ change from 6.2 to $45.3 \mathrm{nT}, S E_{F}^{I G R F}$ change from 16.8 to $50.6 \mathrm{nT})$.

\section{Conclusions}

The regional geomagnetic field over Vietnam and adjacent region was modelled using the SCHA method and geomagnetic data recorded on board of CHAMP and Swarm satellites, during magnetic quiet periods.

It was shown that the optimal parameters of the SCHA model for this region are: external field $K_{\text {ext }}=2$, internal field $K_{\text {int }}=8$, a half-cap angle of $20^{\circ}$ and dimension of data grid $0.2^{\circ} \times 0.2^{\circ}$. Meshing data reduces the RMS between the regional magnetic field model and the input data compared to the non-grid data, namely the difference of the RMS between two processing procedures are 2.25 $\mathrm{nT}$ for CHAMP data (total field $\mathrm{F}$ ) and $1.63 \mathrm{nT}$ for Swarm data, correspondingly.

- The regional geomagnetic field elements D, I, $\mathrm{X}, \mathrm{Y}, \mathrm{Z}$ and $\mathrm{F}$, exhibit similar pattern for the two epochs 2007.0 and 2015.0. The RMS between the model and CHAMP observations are greater than between the model and Swarm observations 3.23 arc $\min , 2.14$ arc min, 4.15 $\mathrm{nT}, 4.64 \mathrm{nT}, 5.31 \mathrm{nT}, 12.52 \mathrm{nT}$ and $2.95,1.83$, $3.22,3.83,4.41,11.54$ for the components, respectively.

- The geomagnetic field intensity $E_{F}^{S C H A}$ from SCHA model varies between -90 and $98 \mathrm{nT}$ for epoch 2007.0 and between -139 and $143 \mathrm{nT}$ for epoch 2015.0 with the wavelength of about 1000-3000 km and their morphology is similar. The field from the SCHA model consists of a crustal field and a party of the core field. The results confirm the stability of the SCHA method and it is well-known technique for modelling of regional geomagnetic field.

- The time variation of the regional magnetic field in the period 2007-2015, calculated from the SCHA method is quite similar to the secular variation from the IGRF-12 model, but with a larger amplitude of about $10 \mathrm{nT}$ (total field) as in the territory of Vietnam.

- The SCHA method used in this paper once again confirms its effectiveness in building a regional magnetic field model that serves well for calculating magnetic anomalies or other regional studies.

\section{Acknowledgements}

We acknowledge the operational support of the CHAMP mission by the German Aerospace Center (DLR). We would like to thank ESA for providing prompt access to the Swarm data. This research was supported by the Vietnam Academy of Science and Technology (VAST05.01/18-19).

\section{Author statement}

Dr. Thanh, main author, carried out the calculations, wrote the manuscript. Dr. Minh gave the idea for the content of paper. Dr. Christine and Prof. Doumbia provided satellite data, improved the manuscript. Prof. Chau and Ms. Dung helped the computations. All authors discussed the results and contributed to the final manuscript.

\section{References}

An Z C 2003 Spherical cap harmonic model of the Chinese geomagnetic reference field for 1936; Chinese J. Geophys. 46(5) 624-627.

De Santis A, Battelli A O and Kerridge D J 1990 Spherical cap harmonic analysis applied to regional field modelling for Italy; J. Geomag. Geoelectr. 42 1019-1036.

De Santis A, Torta J M and Lowes F J 1999 Spherical cap harmonics revisited and their relationship ordinary spherical harmonics; Phys. Chem. Earth $(A) 24$ 935-941.

Di C Z, Gu Z W, Bernardo M S, Chen B, Carina G L, Zhang Y, Xin C Z and Gao Z T 2011 The study of magnetic field models for Philippines and its neighboring regions; Chinese J. Geophys. 54 508-515.

Duka B 1998 Comparison of different methods of analysis of satellite geomagnetic anomalies over Italy; Ann. Geofis. 41 49-61.

Feng Y, Sun H, Jiang Y, Jiang Y, Liu B J, Jiang Y, Liu Z W, Ye M C, Wang H S and Li X M 2016 Spherical cap harmonic analysis of regional magnetic anomalies based on CHAMP satellite data; Appl. Geophys. 13(3) 561-569, https://doi.org/10.1007/s11770-016-0567-8.

Gu Z, Zhan Z, Gao J, Han W, An Z, Yao T and Chen B 2006 Geomagnetic survey and geomagnetic model research in China; Earth planet. Space 58 741-750.

Haines G V 1985a Spherical cap harmonic analysis; J. Geophys. Res. $902583-2592$.

Haines G V 1985b Spherical cap harmonic analysis of Geomagnetic Secular Variation over Canada 1960-1983; J. Geophys. Res. 90 12,563-12,574. 
Haines G V and Newitt L R 1997 The Canadian geomagnetic reference field 1995; J. Geomag. Geoelectr. 49 $317-336$.

Korte M and Haak V 2000 Modelling European repeat station and survey data by SCHA in search of time-varying anomalies; Phys. Earth Planet. Inter. 122 205-220.

Korte M and Holme R 2003 Regularization of spherical cap harmonics; Geophys. J. Int. 153 253-262.

Kotzé P B and Barraclough D R 1997 Modelling and analysis of POGS data over Southern Africa by spherical cap harmonic analysis; J. Geomag. Geoelectr. 49 441-452.

Kotzé P B 2001 Spherical cap modelling of Oersted magnetic field vectors over Southern Africa; Earth Planet. Space $\mathbf{5 3}$ $357-361$.

Newitt L R and Haines G V 1989 A Canadian geomagnetic reference field for epoch 1987.5; J. Geomag. Geoelectr. 41(2) 249-260.

Langel R A and Estes R H 1985 Large-scale near-Earth magnetic fields from external sources and the corresponding induced internal field; J. Geophys. Res. 90 2487-2494.

Rotanova R M and Odintsov S D 1999 Model of the MAGSAT Magnetic Anomaly Spherical Cap Harmonic Analysis; Phys. Chem. Earth (A) 24 455-459.

Qamili E, De Santis A, Cianchini G, Duka B, Gaya-Piqué L R, Dominici G and Hyka N 2010 Two geomagnetic regional models for Albania and south-east Italy from 1990 to 2010 with prediction to 2012 and comparison with IGRF-11; Earth Planet. Space 62 833-841.

Qiu Y, Wang Z, Jiang W, Zhang B, Li F and Guo F 2017 Combining CHAMP and Swarm satellite data to invert the lithospheric magnetic field in the Tibetan Plateau; Sensors (Basel) 17(2) pii: E238, https://doi.org/10.3390/ s170202387.

Thébault E, Schott J J, Mandea M and Hoffbeck J P 2004 A new proposal for spherical cap harmonic modelling; Geophys. J. Int. 159 83-103, https://doi.org/10.1111/j.1365246X.2004.02361.x.

Corresponding editor: Arkoprovo Biswas
Thébault E and Gaya-Pique L 2008 Applied comparisons between SCHA and R-SCHA regional modelling techniques; Geochem. Geophys. Geosyst. 9(7), https://doi. org/10.1029/2008GC001953.

Thébault E, Vigneron P, Maus S, Chulliat A, Sirol O and Hulot G 2013 Swarm SCARF dedicated lithospheric field inversion chain; Earth Planet 65 1257-1270.

Thébault E, Finlay C C, Beggan C D, Alken P, Aubert J, Barrois O, Bertrand F, Bondar T, Boness A, Brocco L, Canet E, Chambodut A, Chulliat A, Coïsson P, Civet F, Du A, Fournier A, Fratter I, Gillet N, Hamilton B, Hamoudi M, Hulot G, Jager T, Korte M, Kuang W, Lalanne X, Langlais B, Léger J, Lesur V, Lowes F J, Macmillan S, Mandea M, Manoj C, Maus S, Olsen N, Petrov V, Ridley V, Rother M, Sabaka T J, Saturnino D, Schachtschneider R, Sirol O, Tangborn A, Thomson A, Tøffner-Clausen L, Vigneron P, Wardinski L and Zvereva T 2015 International geomagnetic reference field: The 12th generation; Earth Planet. Space, https://doi.org/10.1186/s40623-015-0228-9, 67-79.

Torta J M, Garcia A M and De Santis A 1993 Geomagnetic reference field for Spain at 1990; J. Geomag. Geoelectr. 45 $573-588$.

Torta J M, De Santis A and von Frese R R B 2002 A model of the secular change of the geomagnetic field for Antarctica; Tectonophys. 347 179-187.

Tozzi, De Santis A and Luis-Ricardo Gaya-Piqué 2013 Antarctic geomagnetic reference model updated to 2010 and provisionally to 2012; Tectonophys. 585 13-25.

Verbanac G 2007 On regional modelling of the main geomagnetic field; Geofizika 24 1-27.

Verbanac G, Korte G M and Mandea M 2009 Four decades of European geomagnetic secular variation and acceleration; Ann. Geophys. 52 487-503.

Vervelidou F, Thébault E and Korte M 2018 A high resolution lithospheric magnetic field model over southern Africa based on a joint inversion of CHAMP, Swarm, WDMAM and ground magnetic field data; Solid Earth 9 897-910. 